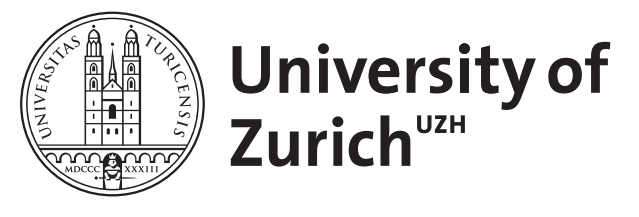

\title{
Labor market segmentation
}

Berndt, Christian

\begin{abstract}
Labor market segmentation theories arose as an alternative to neoclassical notions of labor and labor markets in the 1970s. After briefly revisiting the strengths and the weaknesses of this approach, the article discusses more recent developments around the question of difference and diversity in labor markets, directing attention to three key developments associated with the rise of neoliberal capitalism: (i) the formation of entrepreneurial subjectivities and the treatment of labor as a diverse human resource; (ii) the blurring of the boundaries of the business firm and the implications for labor; and (iii) offshoring and "governance at a distance."
\end{abstract}

DOI: https://doi.org/10.1002/9781118786352.wbieg0556

Posted at the Zurich Open Repository and Archive, University of Zurich ZORA URL: https://doi.org/10.5167/uzh-136722

Book Section

Accepted Version

Originally published at:

Berndt, Christian (2017). Labor market segmentation. In: Richardson, Douglas; Castree, Noel; Goodchild, Michael F; Kobayashi, Audrey; Liu, Weidong; Marston, Richard A. The international encyclopedia of geography: people, the earth, environment and technology. Hoboken: John Wiley Sons, online.

DOI: https://doi.org/10.1002/9781118786352.wbieg0556 


\title{
Labor Market Segmentation
}

Christian Berndt, University of Zurich

christian.berndt@geo.uzh.ch

18 June 2014

Revised manuscript submitted for publication in "The Wiley-AAG International Encyclopedia of Geography"

\begin{abstract}
Labor market segmentation theories arose as an alternative to neoclassical notions of labor and labor markets in the 1970s. After briefly revisiting the strengths and the weaknesses of this approach, the article discusses more recent developments around the question of difference and diversity in labor markets, directing attention to three key developments associated with the rise of neoliberal capitalism: (1) The formation of entrepreneurial subjectivities and the treatment of labor as a diverse human resource; (2) The blurring of the boundaries of the business firm and the implications for labor; and (3) offshoring and "governance at a distance".
\end{abstract}

\section{Main Text}

It has long been argued in the scholarly literature that the assumption that labor power is allocated according to the same universal laws that match the supply and demand of ordinary goods such as apples is fundamentally wrong. Yet this critique notwithstanding, this is exactly how labor markets are imagined and represented in public discourse and in our daily life. This is a good example of how orthodox economics works: Statements like these are not about how real labor markets operate, rather they are about how labor markets should work.

It is against this truncated notion of labor and labor markets that scholars of different theoretical stripes put forward more realistic and complex representations. A prominent example is the heterogeneous body of work that has been assembled under the label "labor market segmentation theory" which emerged as a leading alternative to standard economic thinking in the 1970s. The various segmentation approaches share an understanding of the labor market as a multiple entity, fragmented into separate submarkets that subject market participants to different rules and work according to different logics. These submarkets provide employment opportunities that differ markedly in quality, resulting in a corresponding compartmentalization of the labor force into workers of higher and lower value. The idealized distinction between primary and secondary sectors of the labor markets was subsequently widened to account (1) for differentiation within submarkets; (2) for a sensitivity for the extent to which segmentation is deeply gendered and racialized, with white, middle-aged to older men dominating the primary market, and women, young people and ethnic/racial minorities the secondary one; and (3) for an awareness of the crucial role of social reproduction, as scholars pointed to encouragement in the family, by peers and in educational institutions (Peck 1996, Reich et al. 1973).

Scholars across the disciplines have engaged with labor market segmentation theories, providing an overview of the evolution of this perspective, and pointing to its strengths and also its weaknesses. Segmentation theorists have been criticized for explaining labor stratification almost exclusively as a capital-driven process, attributing it either to the changing technical imperatives of the production process, or to the controlling and disciplinary strategies of 
employers. Power asymmetries loom large in the latter account, capital implementing strategies of "divide and conquer" (Reich et al. 1973, 361), exploiting existing ethnic and gender differences in the workforce, and in so doing actively reproducing and deepening these cleavages (Peck 1996, 53-54).

In geography it has mainly been Jamie Peck who introduced labor market segmentation into the discipline and addressed the blind spots of its various strands. This refers above all to the insight that labor segmentation processes are contingent both in time and space. Historically, interest in segmented labor markets emerged roughly at a time when the transition from competitive to monopoly capitalism became palpable in industrial societies and in labor markets. With regard to space, feminist geographers referred to the role that spatial relations between home and work play in giving women unequal access to the labor market (e.g. Hanson, and Pratt 1995). In addition to this, labor market arrangements were embedded in decidedly national territorial frames. This was the time of economies that combined cross-border mobility of finished goods with limited mobility of labor and capital, a national compromise that was to be challenged in the wake of the cascading rounds of outsourcing and offshoring that gave rise to the contemporary global division of labor. The emergence of what has variably been termed "network capitalism" (Boltanski, and Chiapello 2005) or "supply chain capitalism" (Tsing 2009) posed new challenges for the "problem of labor", challenges that evoke a peculiar mix of old and new divide and rule strategies.

As commodity production morphed into a dizzying array of intertwined supply chains, production networks and markets for semi-finished goods, subsequent generations of segmentation theorists put forward more complex explanations. There has been an increasing awareness that the primacy given to capital hides from view that employers are often simply reacting to changes in product markets, production processes, labor market constraints and the regulatory environment rather than proactively formatting their environment according to their needs. With regard to labor supply, capital may put to profitable use social differences in the labor force, but does not create these cleavages in the first place. All this led to a more detailed engagement with the "supply side" of labor market, with labor being given a somewhat more active role. This crucially included a more systematic account of social reproduction (e.g. occupational socialization in the family, household division of labor), the regulatory role of the state at various spatial scales, and the role of organized labor (Hanson, and Pratt 1995, Peck 1996, 57).

These developments notwithstanding, however, labor segmentation theory appears to have lost traction in the scholarly community. More recent reviews within human geography and other social science disciplines rarely go beyond the comprehensive account given in Peck's seminal contribution. This may at least partly be a reflection of the shortcomings of a still predominantly demand-side focused and capital-driven approach at a time of increasing geographical and social complexity. The remainder of the discussion therefore adopts a more flexible approach, putting emphasis on the question of difference and diversity in labor markets more generally. In doing so, attention is directed to three key developments associated with the rise of neoliberal capitalism.

\section{Entrepreneurial subjects and labor as a diverse human resource}

The first of these developments concerns the evolution of labor management strategies. In particular, this refers to recent developments within economic practice disciplines such as strategic human resource management, and the emergence of diversity management strategies. 
With the rise to prominence of the resource-based theory of the firm after World War II, Human Resource Management emerged as a booming social science discipline. In its dominant mainstream variant, HRM is mainly about techniques to raise the commitment and performance of workers. It is generally assumed in the HRM mainstream that the interests of workers and employers are congruent and that both sides profit from good HRM practices.

The rise of HRM has a lot to do with the changing economic environment and the uncertainties arising from this. Insofar as individual knowledge and creativity, and the social networks of the workforce replaced hard assets as key factors deciding about economic success, traditional management tools declined in importance. Because of the non-calculability of these resources, there was an urgent need to develop different means of evaluation. The solution was provided by HRM: It is the individual worker, his/her skills and his/her social connectivity that is becoming ever more important. In so doing, HRM developed into a powerful calculative tool to evaluate employees according to their individual capabilities.

Underlying the transformation is a shift in the way that workforce difference is handled. For the management of the Fordist corporation the key to efficient production was to organize labor in a way that social differences appeared to recede into the background. A key reason for this was the introduction of new managerial and organizational practices inside the firm. Wellelaborated, deeply stratified internal labor markets allowed the integration of a wide array of workers in a single organizational entity, where production engineers, shop floor workers, administrative secretaries, accountants, cleaners and so on all found their place in an extended corporate hierarchy. In so doing, the corporate hierarchy produced an environment of controlled diversity between workforce segments, each segment different enough to allow discretionary working conditions and wages, and homogenized internally to an extent that permitted fairly standardized recruitment strategies. Workers played their part in this environment of almost total control, identifying with the respective vocational framework and the formal educational credentials that circumscribed each segment in the corporate hierarchy. All this was embedded in the Fordist welfare state that provided the environment in which corporate capital could enlist labor unions and secure the collaboration of privileged workers in the realization of corporate profits in a general climate of social inclusion. Of course, underneath the surface of occupational and functional stratification, the corporate organization both profited from and reproduced structures of social difference, by excluding women or ethnic minorities from waged labor, by limiting labor market access to secondary segments, and by admitting them only to certain positions in the primary sector (Abbott 2006, Fraser 2003, 165).

More recently, however, the role of social difference in the private firm has been reevaluated: In many countries of the Global North there have been marked shifts in the composition of workforces, manifested in the feminization of employment, the ageing of populations and the increasing presence of migrant labor. It is in the wake of these changes that diversity management emerged as an increasingly popular branch of HRM. A socially and culturally diverse workforce is valued as a competitive asset in its own right and HR departments are expected to actively manage, promote and harness workforce diversity. Rather than just being an add-on to the "labor problem", social differences are actively performed and utilized by HRM practices, making labor possible in today's global production systems. In the newly emerging configuration the discovery of diversity and identity as a corporate asset and resource is underpinned by a liberal notion of equality. Workers are apparently treated as separate individuals, capable of different, unequal performances. Accordingly, valuable resources controlled by employees due to their perceived gender or ethnic position are individualized. It is 
only those identity prescriptions that fit into the representation of workers as entrepreneurs that are acknowledged. Against this, critical observers point to the persistence of racialized and sexbased segregation at the workplace and argue that by individualizing "diversity", representations like these successfully veil persisting power asymmetries. In particular they point out that diversity management practices ignore collective sources of disadvantage, privilege those in society who happen to display the right mix of individual character traits, and render attempts to make claims based on collective, social aspects of identity positions extremely difficult (Gedalof 2013).

A concrete manifestation of this is the presence in many workplaces of a mosaic of employment statutes, with extreme diversity of wages and other entitlements. The initiative is with capital and management in these processes, allowing the continuation of divide and rule strategies in different form. However, just as in the case of segmentation during Fordism, division is never enough for effective rule. There is a corresponding necessity for (re)integration into a larger common frame and entity. The previous stratification of the workforce in primary and secondary labor markets was embedded in national systems of labor regulation. Today, the common ground is being provided by the corporate community, the mythical "firm as a family" transported in the mission statements and slogans that aim to rally workers behind a greater good: the globally competitive firm.

The new corporate world continues to distinguish core from peripheral workers. The latter include "unskilled" production work that moved to locations in the Global South, the temporary labor working "onshore" often next to more privileged colleagues, the rising labor market precariate unable to find anything else than spurious employment, and the unemployed. It is in these disadvantaged segments of the work force that conditions accumulate which are not valued highly in today's resource-driven organizations: workers who arrive at the labor market with the wrong set of qualifications and skills, who find it difficult to comply with the flexibility, communicative skills, mobility and total commitment demanded by management (Boltanski, and Chiapello 2005, 231-232).

It is frequently argued that it is the readiness on the part of workers to perform the subjectivities inscribed by the omnipresent rhetoric of workers as resources that explains part of the success of the new world of work. In her account of the type of labor that is mobilized in what she terms "supply chain capitalism", anthropologist Anna Tsing (2009) is adamant that tiring, repetitive and physical work has certainly not disappeared. However, the problem of labor (i.e. the need to secure the consent and collaboration of wage-earners in order to realize capitalist profits) is now addressed in a different way. It is less being done through the collective, political integration of workers into a society that equated economic and technological progress with social justice, but increasingly by means of developing entrepreneurial projects of self-realization that emphasize individual performance, responsibility and mobility. In this logic, the individual worker's autonomy is fostered as a means to her control, turning labor into active agents of selfregulation (Berndt 2010, Fraser 2003, 165).

Work tasks and job profiles are framed in particular ways in the corporate family. They are gendered, ethnicized, and coded according to nationality and age. And workers establish themselves by performing those very attributes. An investment banker must perform competitiveness, unscrupulousness and readily embrace risk, a care worker empathy, affect and availability. It is this double process of self-exploitation and external inscription that makes supply chain capitalism possible (Tsing 2009, 158). 


\section{Supply chains and the de-centering of the business firm}

A second challenge concerns the ongoing blurring and reconfiguration of the organizational boundaries of the firm. The familiar argument is that the rigid corporate hierarchy has gradually given way to more spurious organizational designs, variably discussed with reference to concepts such as heterarchy, project-based forms of organization or the network firm. As a result of this, it is no longer individual firms that compete with each other, but rather networks of firms bound together in ever more complex supply and value chains.

There is broad agreement in the literature that oligopolistic chain- and network-like governance structures are the key organizational units in today's global economy. The rise in importance of practice disciplines such as logistics and supply chain management that deliberately extend governance regimes beyond the boundaries of the individual firm is testimony to this development. This development notwithstanding, however, it is often the case that a particular successful firm assumes the position of a role model for a specific configuration of capital-labor relations (e.g. Fordism, Toyotism). In the case of the network perspective with is imaginations of supply chains, logistics, track'n'trace technologies, this role is most frequently assigned to Wal-Mart (Tsing 2009, Boltanski, and Chiapello 2005, 223).

The apparently clear-cut boundary around the business firm is additionally dissolved with a view to what has traditionally been regarded as lying outside the realm of the formal economy, that is, the realm of social reproduction. This concerns both the emerging boundary zone of precarious, "informal" and "illegal" work that feeds the apparently formal production chains and networks, as well as work that has been shifted from waged employment into a wide array of non-wage forms, be it voluntary, domestic, hobby, and forced work (Abbott 2006, 307-308). Social differences play a crucial role in maintaining both the hidden extension of ostensibly formal processes of the production of goods and services into less tightly regulated realms as well as successful attempts by economic and political decision-makers to reproduce an apparent clear-cut boundary between the economy proper and that which lies beyond. To a large extent it is the migrant woman that provides the labor in the latter realm, for instance as cleaner, care worker, au pair or maid (e.g. Hochschild 2002). What those employment relations have in common is an expectation of almost unlimited flexibility and availability, connected with what André Gorz (2004, 27; my translation) termed "total mobilization of capacities and skills, including sentiments and emotions".

One result of this is a blurring of the boundary between work and leisure time, between emotional engagement and the role of a professional, detached service worker. The task to police those boundaries is largely delegated to the worker herself. It is the individual care worker, cleaner or maid who is responsible for making sure that she does not involve herself too much emotionally, for regulating her working time, or for making sure that the challenge to navigate five or six different workplaces per day remains manageable. Empirical research illustrates that these practices easily turn into self-exploitation, in so doing making the low wage and apparently unskillable character of this work possible in the first place.

\section{Governing at a distance: The offshore logic of supply chain capitalism}

A key reason for the changing role of social difference in the labor market has arguably been the growing social and spatial complexity of production, distribution and consumption outlined above. As those organizational constellations are far more difficult to control than individual firms, the traditional solution of relying solely on stabilization via standardization can no longer be a viable option. This is another reason for the more indirect and subtle way in which to 
organize labor in today's supply chains and production networks, a way of disciplining that governs workers "at a distance" (Fraser 2003, 167).

There is both a social and a spatial dimension to this. Starting with the former, this concerns the move towards more autonomy and responsibility for the worker, and a corresponding possibility for corporate decision-makers to detach themselves from the consequences of their actions. However, this "social distancing" is only one side of the coin, for the apparent organizational detachment is going hand and hand with tighter monitoring of other features of the supply chain, for instance those involving prices and marketing arrangements (Tsing 2009, 156). And both moments come together if one looks at the increasingly prominent role of technological and quality standards in supply chains. At the same time as firms transfer responsibility for product quality and consumer satisfaction to workers and subcontractors, they increase the pressure on those actors with the implementation of ever more sophisticated track'n'trace technologies. These devices do not allow the slightest deviation from the script and do not forgive the tiniest mistake or lapse of concentration, making it possible to confront workers with their performance long after the product in question has left the shopfloor or workplace. Supply chain technologies create an environment in which periods of idleness are abolished, creating a potentially unlimited repository of deeds and gestures that make workers subject to remote control and that are constitutive of "governance-at-a-distance" (Boltanski, and Chiapello 2005, 247).

The geographical materialization of this is "offshoring". Understood in an abstract form as a defining feature of contemporary capitalism, offshoring involves a double framing process. First, the articulation of people, things and regions with global supply chains and markets, by way of transforming heterogeneity and contingency into productive labor, advanced production sites, special economic zones, and by disarticulating those elements from their social and spatial contexts. And second, a new moment of dis/entanglement that allows powerful interests to decouple the profitable exchange of labor and goods in global supply chains from the responsibility and liability for the social and geographical implications of these operations (Appel 2012). The attention turns to mobile standards, templates and infrastructures as boundarymaking objects. And it is with the help of various registers of social difference that this redrawing of boundaries is accomplished. This occurs by ritualized evocations of age-old stereotypes, such as the one manifested in the representation of southern female workers as "disposable" and "unskillable" (Wright 2006). Another example is the racialized legitimization of "old" disciplinary labor regimes in ostensibly advanced production sites, with hints at cultural traits that are apparently unsuitable for modern production and the corresponding paternalist "obligation" to be a strict northern father to southern factory daughters.

This is made visible with the help of ostensibly objective technologies that calculate defects per million parts, scrap rates or productivity numbers. It is because these dis/entanglements are extremely complex and are constantly prone to fail and overflow that they require continuous logistical effort and financial investment. Methodologically, it is multi-sited ethnographic research, following things, people and ideas and the plurality of relations they assemble, that is able to shed empirical light into the realization of new regimes of labor control and stratification. Such an approach is also capable of illustrating how new organizational models travel to less privileged workplaces, above all in the Global South and how a key observation of early labor market segmentation theories, namely the dual labor market, has assumed a new global form. The latter point takes up the observation that less desirable and overflow work continuous to be outsourced to the Global South, either by moving jobs to 
locations in countries such as China or Mexico, or by mobilizing largely female migrant labor for reproductive tasks in northern households.

\section{SEE ALSO:}

Corporations and Conditions of Work / Flexible Labor Markets / Gender, Work, Employment / Inequality / Labor Geographies and the Corporation / Labor geography / Labor Market.

\section{References and Further Readings}

Abbott, Andrew. 2006. "Sociology of work and occupations." In International Encyclopedia of Economic Sociology, edited by Jens Beckert, and Milan Zafirovski, 307-330. London:

Routledge. Appel, Hannah. 2012. Offshore work: Oil, modularity, and the how of capitalism in Equatorial Guinea. American Ethnologist 39 (4): 692-709. http://dx.doi.org/10.1111/j.15481425.2012.01389.x.

Berndt, Christian. 2010. "Methodological nationalism and territorial capitalism: Mobile labor and the challenges to the 'German Model'." In Handbook of Employment and Society: Working Space, edited by Susan McGrath-Champ, Andrew Herod and Al Rainnie, 290-308. London: Edward Elgar.

Boltanski, Luc, and Eve Chiapello. 2005. The New Spirit of Capitalism. London: Verso. Fraser, Nancy. 2003. "From discipline to flexibilization? Rereading Foucault in the shadow of globalization." Constellations 10 (2): 160-171. http://dx.doi.org/10.1111/1467-8675.00321. Gedalof, Irene. 2013. "Sameness and difference in government equality talk." Ethnic and Racial Studies 36 (1): 117-135.

Gorz, André. 2004. Wissen, Wert und Kapital: Zur Kritik der Wissensökonomie. [Knowledge, value and capital: A critique of the knowledge economy] Zürich: Rotpunktverlag. Hanson, Susan, and Geraldine Pratt. 1995. Gender, Work, and Space. New York: Routledge. Hochschild, Arlie. 2002. "Love and Gold." In Global Woman: Nannies, Maids and Sex Workers in the New Economy edited by Barbara Ehrenreich, und Arlie Hochschild, 15-30. London: Granta Books. Peck, Jamie. 1996. Work-place: The social regulation of labor markets. New York: Guilford Press.

Reich, Michael, David, Gordon, and Richard Edwards. 1973. "A theory of labor market segmentation." The American Economic Review 63 (2): 359-365.

Tsing, Anna. 2009. "Supply chains and the human condition." Rethinking Marxism 21 (2): 148176.

Wright, Melissa W. 2006. Disposable Women and Other Myths of Global Capitalism. New York: Routledge.

\section{Key Words}

corporate geography 
economic geography

labor geography

production

stratification and inequality identity 